\title{
Assessment of personal exposure to infectious contaminant under the effect of indoor air stability
}

\author{
Xiaorui Deng ${ }^{1,2} \cdot$ Guangcai Gong $^{1,2}\left(\right.$ C) $\cdot$ Shanquan $\mathrm{Chen}^{3} \cdot$ Xizhi He $^{1,2} \cdot$ Yongshen Ou $^{1,2} \cdot$ Yadi Wang $^{1,2}$ \\ Received: 5 November 2020 / Accepted: 10 March 2021 / Published online: 23 March 2021 \\ (C) The Author(s), under exclusive licence to Springer-Verlag GmbH Germany, part of Springer Nature 2021
}

\begin{abstract}
The objective of this study is to understand the effect of indoor air stability on personal exposure to infectious contaminant in the breathing zone. Numerical simulations are carried out in a test chamber with a source of infectious contaminant and a manikin (Manikin A). To give a good visual illustration of the breathing zone, the contaminant source is visualized by the mouth of another manikin. Manikin A is regarded as a vulnerable individual to infectious contaminant. Exposure index and exposure intensity are used as indicators of the exposure level in the breathing zone. The results show that in the stable condition, the infectious contaminant proceeds straightly towards the breathing zone of the vulnerable individual, leading to a relatively high exposure level. In the unstable condition, the indoor air experiences a strong mixing due to the heat exchange between the hot bottom air and the cool top air, so the infectious contaminant disperses effectively from the breathing zone. The unstable air can greatly reduce personal exposure to the infectious contaminant in the breathing zone. This study demonstrates the importance of indoor air stability on personal exposure in the indoor environment and provides a new direction for future study of personal exposure reduction in the indoor environment.
\end{abstract}

Keywords Personal exposure $\cdot$ Indoor air stability $\cdot$ Breathing zone $\cdot$ Computational fluid dynamics (CFD)

\section{Introduction}

Over the last two decades, we have experienced three severe airborne coronaviruses diseases, 2002-2003 severe acute respiratory syndrome (SARS), 2012-2015 middle eastern respiratory syndrome (MERS) and the ongoing coronavirus disease 2019 (COVID-19). This raised the concern to the possible emergence of new airborne infectious disease, and thus a sustained preparedness is needed. At present, to cope with the COVID-19 pandemic, people have been asked to stay at home

Responsible editor: Lotfi Aleya

Guangcai Gong

gcgong@hnu.edu.cn

1 Department of Building Environment and Energy Engineering, College of Civil Engineering, Hunan University, Changsha 410082, Hunan, China

2 Key Laboratory of Building Safety and Energy Efficiency, Ministry of Education, Hunan University, Changsha 410082, China

3 School of Clinical Medicine, University of Cambridge, Cambridge CB2 3EB, UK and keep social distancing from others. This emphasizes the importance of maintaining good indoor environment quality, especially good indoor air quality, as it is closely associated with people's health conditions (Allen et al. 2016; Spengler and Sexton 1983; Fisk 2018; Fisk et al. 2009). In particular, the air quality in the microenvironment around the human body plays a major role in personal exposure to the infectious contaminant (Melikov 2015; Licina et al. 2015; Nielsen et al. 2009). People who are exposed to the infectious contaminant may suffer adverse diseases, including lung dysfunctions, allergic reactions, pulmonary disease and even heart disease (Han et al. 2017; Douwest et al. 2003), so it is important to reduce the quantity of infectious contaminant to protect occupants from airborne infection.

The transmission of the airborne infectious contaminant in the indoor environment is driven by the background airflow in the environment (Bivolarova et al. 2017), for example, the indoor temperature distribution. Gong et al. (2010) classified the indoor air's condition into three types, namely, stable, neutral and unstable. The classification is referred to as indoor air stability or limited space air stability. Gong and Deng (2017) further illustrated the indoor air stability as a measure of the indoor air's capacity to keep the initial inertia 
transmission state. They introduced a dimensionless number, $G c$ number, to determine the indoor air stability condition. $G c$ number is the ratio of temperature or density difference $(g \cdot \partial \rho /$ $\partial g$ ) to the inertia of the air parcel along the vertical direction $(v$ - $\partial v / \partial y)$ and is defined as $G c=g L \Delta T /\left(T_{0} v_{0}^{2}\right)$, where $g$ is the gravitational acceleration, $\mathrm{m} / \mathrm{s}^{2} ; v_{0}$ is the characteristic velocity, $\mathrm{m} / \mathrm{s} ; \Delta T$ is the vertical temperature difference in the room, $K$; $L$ is the room height, $m$; and $T_{0}$ is the characteristic temperature, $K$. When $G c>0$, the indoor air was in stable conditions; when $G c<0$, the indoor air was in unstable conditions; when $G c=0$, the indoor air was in neutral conditions (Deng and Gong 2020; Wang et al. 2014). Stable air is often seen in rooms with floor cooling (Zhou et al. 2019; Olesen 1997) or ceiling heating (Safizadeh et al. 2019), where indoor air often experiences a lock-up effect (Bjørn and Nielsen 2002; Gao et al. 2012), while unstable air environment often occurs in floor-heating (Dehghan and Abdolzadeh 2018) or chilledceiling rooms (Alamdari et al. 1998), where strengthened forced or natural convection occurs (Zhou et al. 2017). A recent novel air-carrying-energy radiant air condition system (Peng et al. 2019, 2020.) is found to be able to create different indoor air stability conditions by adjusting the heating and cooling mode of the terminal. In essence, the vertical temperature difference between the ceiling and the floor of a room would develop an indoor-air-stability-related buoyancy effect that regulates the air distribution in a way that is different from the Archimedes-related buoyancy effect that is caused by the temperature difference between an airflow current and its ambient environment, thereby the indoor air stability was also referred to as the background temperature effect (Gong and Deng 2017). Xu et al. (2015) reported that the decay of the concentration of contaminant in a room was greatly dependent on the indoor air stability, so they suggested that a sufficient consideration of indoor air stability conditions should be included when studying the contaminant distribution in the indoor environments.

Field studies and full-scale experiments have been prevailing in investigating personal exposure to the indoor infectious contaminant (Zhang et al. 2017). Personal monitoring is commonly used to collect personal data for the exposure analysis (Watson et al. 1988); however, sampling devices generally have a long response time that may lead to inaccurate exposure assessment (Kierat et al. 2018). Also, it is difficult for traditional experiment methods to characterize the distribution of airborne infectious contaminant in the vicinity of a person (Taghinia et al. 2015). To address these limitations of the abovementioned research method, the possibility of determining exposure to infectious contaminant by numerical simulation became popular. Computational fluid dynamics (CFD) was first introduced by Nielsen (1975) to predict indoor air distribution and has been used widely in predicting the transport of airborne contaminant in the indoor environment (Gao and Niu 2007; Bjørn and Nielsen 2002; Olmedo et al. 2012; Holmberg and Li 1998).

This study aims to investigate the personal exposure to the airborne infectious contaminant in the breathing zone when the buoyancy in the room is solely driven by indoor air stability conditions, i.e. stable, neutral and unstable. To highlight the objective of the current work, the Archimedes-related buoyancy effect, i.e. the body thermal plume, is excluded. The exposure index, as well as the exposure intensity, is analysed to evaluate the performance of different indoor air stability conditions on reducing personal exposure in the breathing zone.

\section{Methods}

\section{The geometry of the CFD model}

In the present study, the commercial software Fluent has been used to carry out the numerical study. The configuration of the modelled room is illustrated in Fig. 1. The numerical model is established in 1:1 proportion to the real experimental chamber in Hunan University. The length of the experimental chamber is $2.4 \mathrm{~m}$, width is $1.8 \mathrm{~m}$, and the height is $2.6 \mathrm{~m}$. The coordinate is located at the centre of the room. A vulnerable individual (Manikin A) is placed on the cross-section of $z=-0.45 \mathrm{~m}$ conducting an inhaling process through the nose. Manikin A is average-sized women with a height of $1.68 \mathrm{~m}$ (Villafruela et al. 2013). The diameter of the nostril opening is $12 \mathrm{~mm}$. The contaminant source is $1 \mathrm{~m}$ in front of Manikin A at $0.2 \mathrm{~m}$ height, with an area of $112 \mathrm{~mm}^{2}$. To present a better visual illustration of the breathing zone, the contaminant source is illustrated by the mouth of a manikin with the same size as Manikin A.

\section{CFD grid generation}

The geometrical model is divided into three parts as shown in Fig. $1 \mathrm{~b}$. Two cuboids, which are $0.42 \mathrm{~m}$ long, $0.9 \mathrm{~m}$ wide and $1.8 \mathrm{~m}$ high, are established around Manikin A and the contaminant source. The cuboids are meshed with the tetrahedral unstructured mesh method due to the complexity of the manikin body surface. Mesh refinement is performed around the nozzle and the nose. A third cuboid is created between the contaminant source and Manikin A to cover the breathing zone with a length of $1 \mathrm{~m}$, a width of $0.9 \mathrm{~m}$ and a height of $1.8 \mathrm{~m}$. The hexahedral structured mesh method is applied to this region. The rest of the room is meshed by a relatively sparse hexahedral structured mesh to increase calculation speed. A grid independence study was conducted over three grid sizes. Considering the computational accuracy and 
Fig. 1 (a) Configuration of the three-dimensional model room and manikin locations and (b) grid configuration of the computational domain

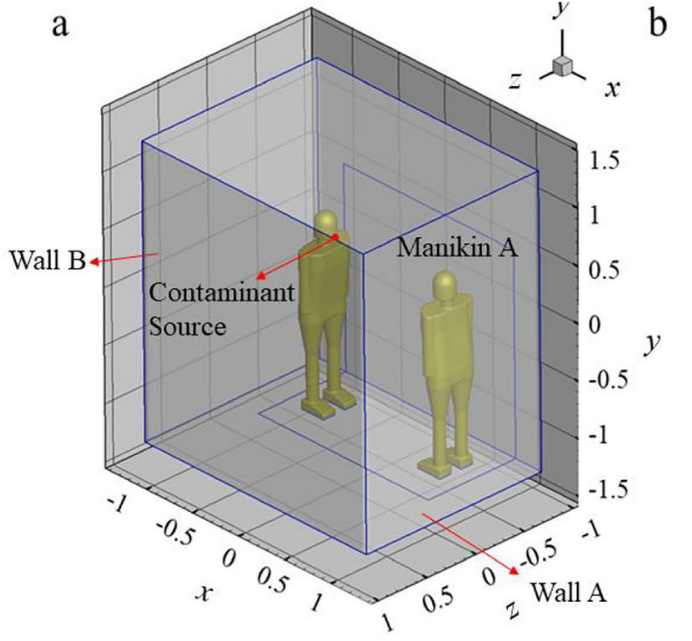

b

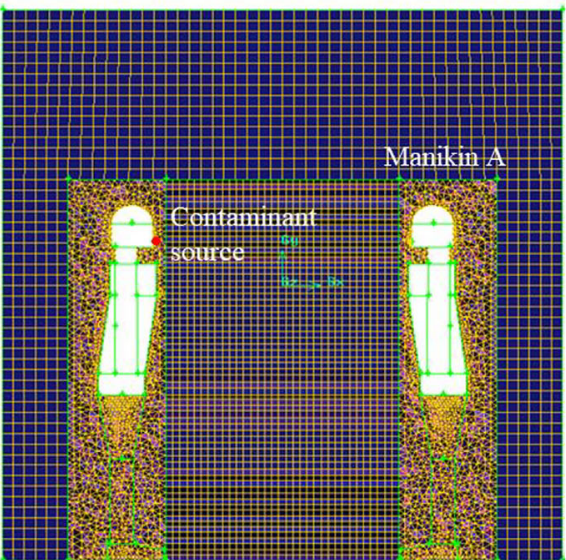

efficiency, a mesh with 509,682 elements in total (Fig. 1b) was used for further simulations.

\section{CFD turbulence model and boundary conditions}

The most common respiratory droplet nuclei were found to range in diameter between 1 and $4 \mu \mathrm{m}$ (Duguid 1946), which allows tracer gas to be a suitable surrogate of exhaled contaminant to reveal the transmission characteristics of airborne infectious contaminant (Ai et al. 2020). As carbon dioxide $\left(\mathrm{CO}_{2}\right)$ is a widely accepted surrogate of the infectious contaminant in indoor air quality studies (Gao and Niu 2004; Sundell et al. 2011), $\mathrm{CO}_{2}$ is used in this study to represent the airborne infectious contaminant from the source. To eliminate the effect of the Archimedes-related buoyancy effect, the convective flow from the body heat is not considered in the current study, and the temperature of the released contaminant is set as the same as the room temperature at $1.5 \mathrm{~m}$ height. The airborne contaminant is constantly released from the source at $3.9 \mathrm{~m} / \mathrm{s}$ in a horizontal direction.

Different indoor air stability conditions in the model room are achieved by adjusting the temperatures on the top and the bottom at different values (Table 1). As the side walls in the corresponding experiment study (Gong and Deng 2017) were made of thermal insulation material with high thermal resistance that can effectively prevent heat from transferring from one side to the other, thus the boundary condition for sidewalls is assumed as adiabatic in the numerical simulation, which is a reasonable boundary condition for well-insulated rooms (Gao and Niu 2004; Gao and Niu 2006; Villafruela et al. 2013;
Fig. 2 Profile of average temperature on adiabatic walls along the vertical direction

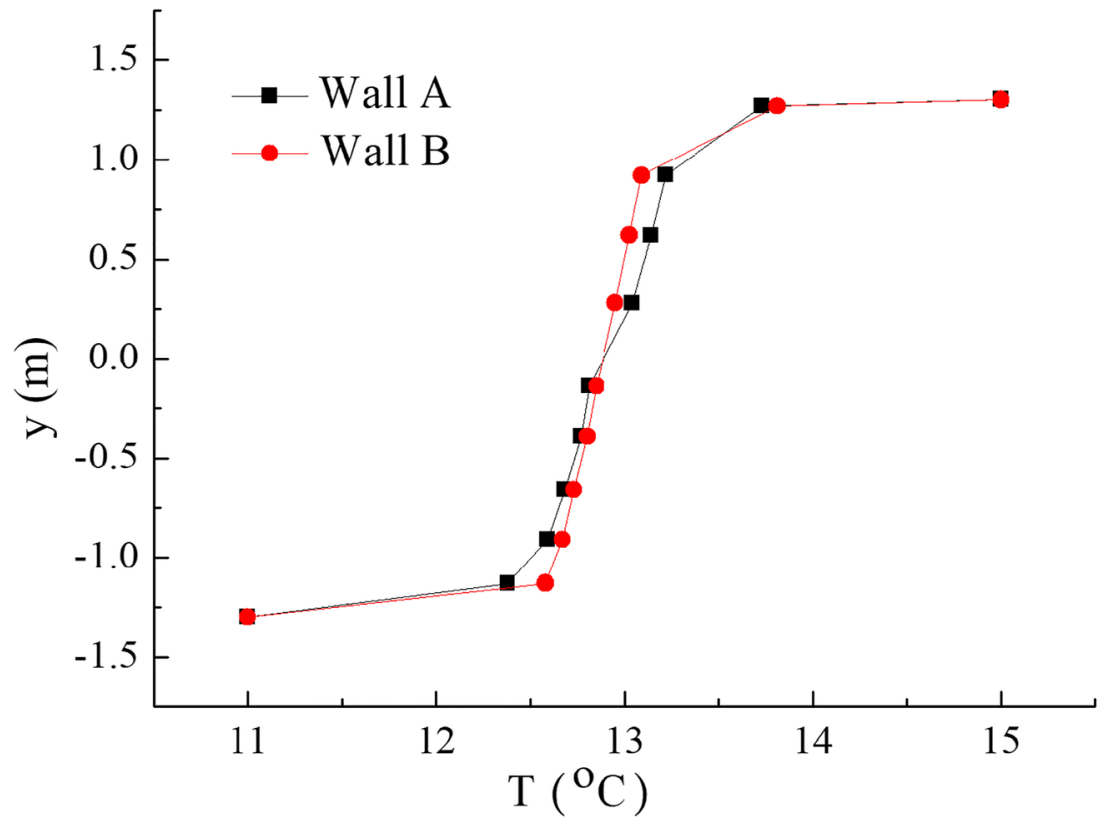


Table 1 The detailed boundary conditions of the CFD simulation

Indoor air stability $\quad T_{\text {top }}\left({ }^{\circ} \mathrm{C}\right) \quad T_{\text {bottom }}\left({ }^{\circ} \mathrm{C}\right) \quad T_{\mathrm{s}}\left({ }^{\circ} \mathrm{C}\right) \quad v_{\text {in }}(\mathrm{m} / \mathrm{s}) \quad C(\%)$

\begin{tabular}{llllll}
\hline Stable & 15 & 11 & & 3.9 & 0.79 \\
Neutral & 13 & 13 & 13 & & \\
Unstable & 11 & 15 & & & \\
\hline
\end{tabular}

Aganovic et al. 2019). Figure 2 illustrates the vertical distribution of temperature over Wall A and Wall B (Fig. 1). Previous studies found that the breathing rate and breathing mode has little influence on the airflow field in the breathing zone (Rim and Novoselac 2009; Pantelic et al. 2009); therefore, to highlight the effect of indoor air stability, the inhaling process is simplified with a fixed velocity of $3.9 \mathrm{~m} / \mathrm{s}$ with an angle of $30^{\circ}$ downward. This simplification was proved to be rational in an exposure study by $\mathrm{He}$ et al. (2011). Table 1 shows the detailed boundary conditions of the CFD simulation.

$T_{\text {top }}$ and $T_{\text {bottom }}$ are the temperature of the top wall and the bottom wall, $T_{\mathrm{s}}$ is the initial temperature of the released contaminant, $v_{\text {in }}$ is the velocity of the inhalation of Manikin A, and $C$ is the initial mass fraction of the contaminant in the releasing airflow.

Reynolds-averaged Navier-Stokes (RANS) equations, together with continuity, momentum, energy equations and species transport equation, are used to calculate the flow field. The RNG $k-\varepsilon$ viscosity model (Chen 1995) is adopted with the standard wall function to close the above equation set. The SIMPLEC algorithm is used with the second-order upwind difference scheme in the calculation process. The value of $y+$ lies in the range of 30-35, which is normal for the use of standard wall function in indoor simulations (Gao and Niu 2006). Exposure analysis is carried out based on the numerical results of $10 \mathrm{~s}$. The steady-state calculation is first conducted to reach an acceptable convergence of the flow field, and then the unsteady calculation is conducted with the time step size $0.001 \mathrm{~s}$.

\section{Validation of the simulation}

The numerical model is validated by the experiment carried by Gong and Deng (2017). Vertical temperature profiles obtained by CFD simulation and experiment results are compared in Fig. 3. Overall, the tendencies of the experiment and simulation results are similar. Relative errors between numerical and experimental results at each height were calculated by Eq. (1). Then the relative errors were averaged for stable, neutral and unstable cases, which were $7.01 \%, 0.72 \%$ and $3.76 \%$, respectively. Given that the measuring errors of the experiments are difficult to estimate, simulation results with average relative errors below 10\% are acceptable (Mendez et al. 2008; He et al. 2011). Also, the temperature of CFD results shows good agreement with experimental results for all three indoor air stability conditions. The established numerical model is therefore used for computing the flow field in the breathing microenvironment.

relativeerror $=\frac{\mid \text { measured }- \text { simulated } \mid}{\text { simulated }}$

\section{Indicators for the exposure assessment}

Exposure index $C$ is used to assess personal exposure under three indoor air stability conditions in the breathing zone, which is defined as:

$C=\frac{C_{i}}{C_{0}}$

In (2), $C_{\mathrm{i}}$ is the concentration in the breathing microenvironment, and $C_{0}$ is the initial concentration of the infectious contaminant.

Exposure intensity $E$ (National Research Council 1991) is introduced to obtain an understanding of the dependence of personal exposure on exposure duration, which is defined as a calculus function of concentration and exposure duration and is expressed as:

$$
E=\int_{t_{1}}^{t_{2}} C(t) d t
$$
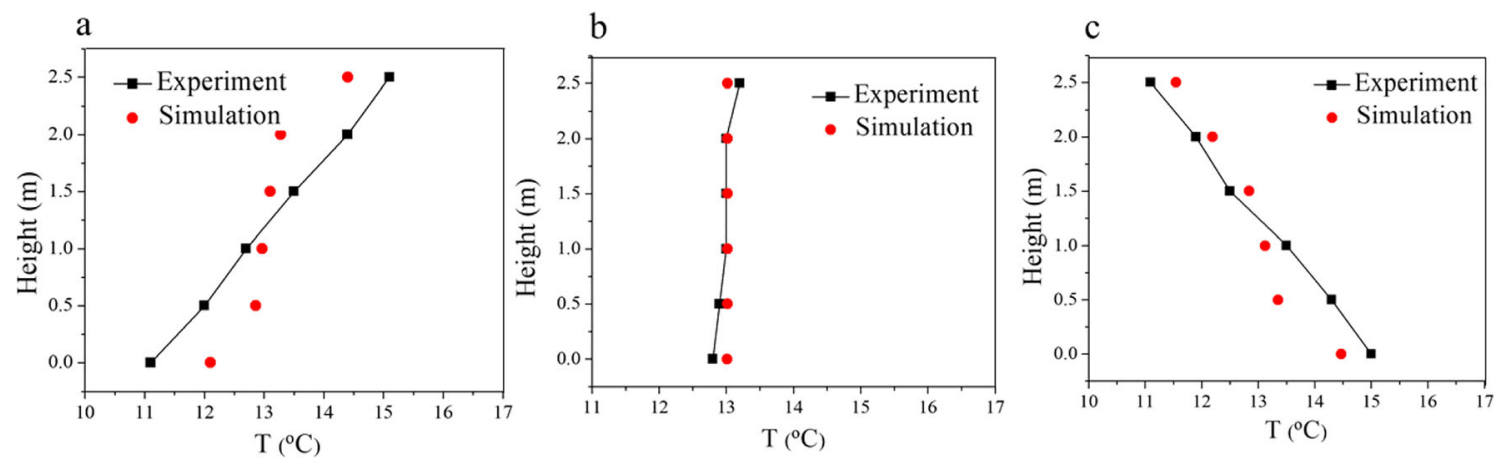

Fig. 3 Data validation for (a) stable condition, (b) neutral condition and (c) unstable condition 
In (3), $C(t)$ is the concentration at any given time, and $t_{2}-t_{1}$ is the duration of exposure.

\section{Results}

\section{Distribution of temperature and vector of velocity in the breathing zone}

Figure 4 shows the temperature distribution and the vector distribution in three indoor air stability conditions, namely, stable, neutral and unstable. In Fig. 4a, clear temperature stratification can be observed. The air temperature at the bottom and top is around $12^{\circ} \mathrm{C}$ and $14^{\circ} \mathrm{C}$, respectively, forming a positive temperature difference of $1.11^{\circ} \mathrm{C} / \mathrm{m}$. This is in correspondence with a stable condition. No temperature difference is observed in Fig. 4b, which corresponds to a neutral condition with the temperature at the bottom and the top $13^{\circ} \mathrm{C}$. The vector distribution of the neutral condition in Fig. 4e shares similar characteristics to that of the stable condition in Fig. $4 \mathrm{~d}$. This is mainly because that the temperature of the released contaminant is the same as the temperature of the ambient air at the releasing height; thus the contaminant is not affected by the Archimedes-related buoyant and sticks to the initial inertial direction, namely, the horizontal direction. In Fig. $4 \mathrm{c}$, the temperature distribution is significantly different from that in the stable condition. The top air is observed around $12.6^{\circ} \mathrm{C}$, and the bottom air is approximately $13.6^{\circ} \mathrm{C}$, resulting in a negative temperature difference $-0.55^{\circ} \mathrm{C} / \mathrm{m}$. This situation well meets the requirement to form an unstable condition. The temperature gradient established in the room developed a convection pattern of the air distribution. The air near the floor area starts to move from warmer areas to cooler areas, and the cooler air on the top descend due to the gravity effect. Therefore, the vertical movement of the indoor air is enhanced. As shown in Fig. 4f, part of the vector of velocity remains in the initial inertial direction, whereas the rest shows a tendency of deviating from the initial inertial direction and transporting towards the upper breathing microenvironment.

\section{Exposure of Manikin A to the infectious contaminant in the breathing zone}

Results obtained on the cross-section of $z=-0.45 \mathrm{~m}$ based on the exposure time of $0.5 \mathrm{~s}, 2 \mathrm{~s}$ and $10 \mathrm{~s}$ are presented in Fig. 5 to analyse the effect of indoor air stability on contaminant distribution and personal exposure in the breathing zone; see also in Gong and Deng (2017).

When Manikin A has been exposed to the infectious contaminant for $0.5 \mathrm{~s}$, little difference in the distribution of exposure index among stable, neutral and unstable conditions is observed. For the stable and neutral condition (Fig. 5a and b, $t=0.5 \mathrm{~s}$ ), the distributions of exposure index spread straightly towards Manikin A; in the unstable condition (Fig. $5 \mathrm{c}, t=0.5$ $\mathrm{s}$ ), a tendency of the exposure index to move upwards can be observed. As the exposure time is only $0.5 \mathrm{~s}$, the contaminant has been just released from the source, so the trajectory is

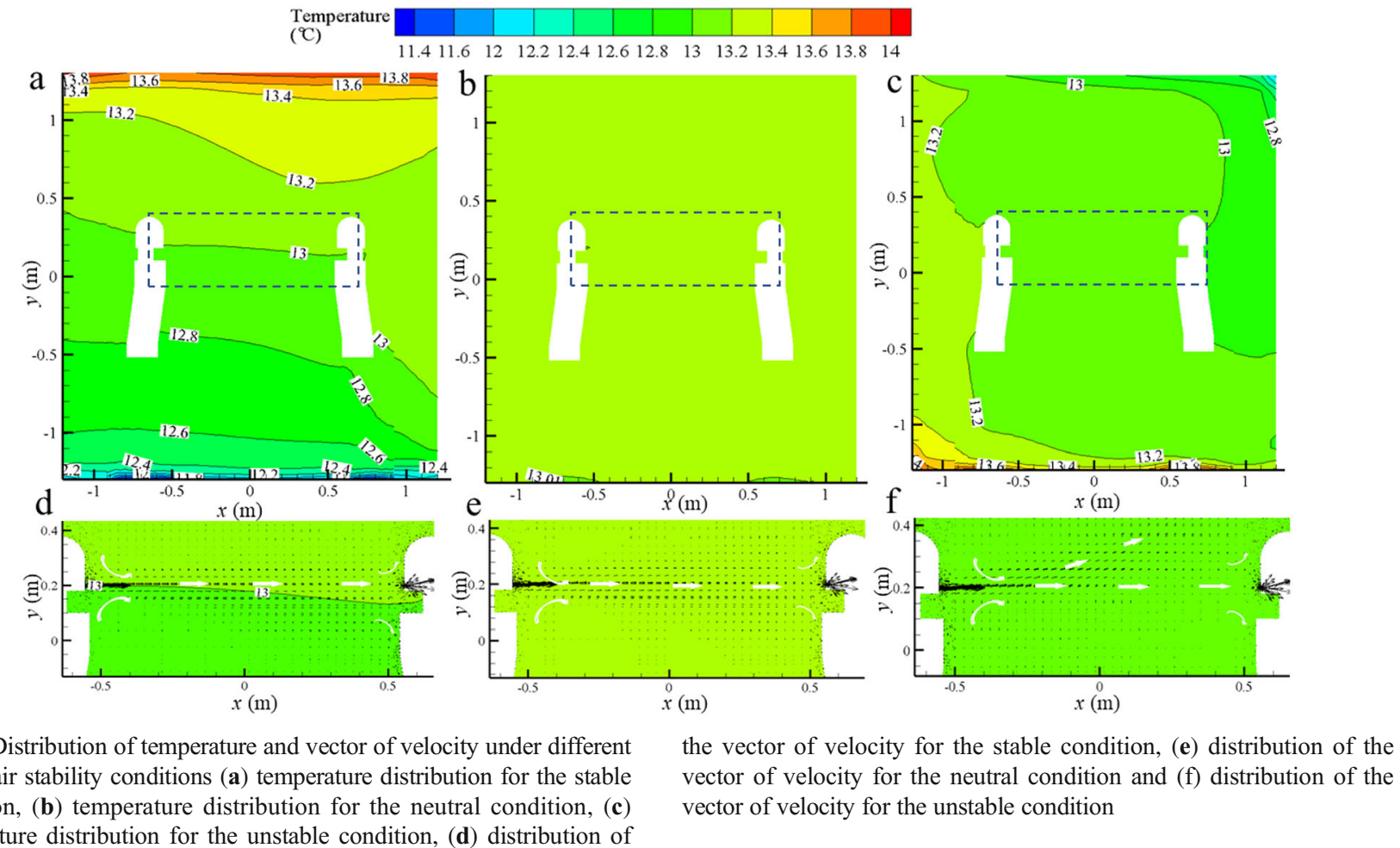

Fig. 4 Distribution of temperature and vector of velocity under different indoor air stability conditions (a) temperature distribution for the stable condition, (b) temperature distribution for the neutral condition, (c) temperature distribution for the unstable condition, (d) distribution of 


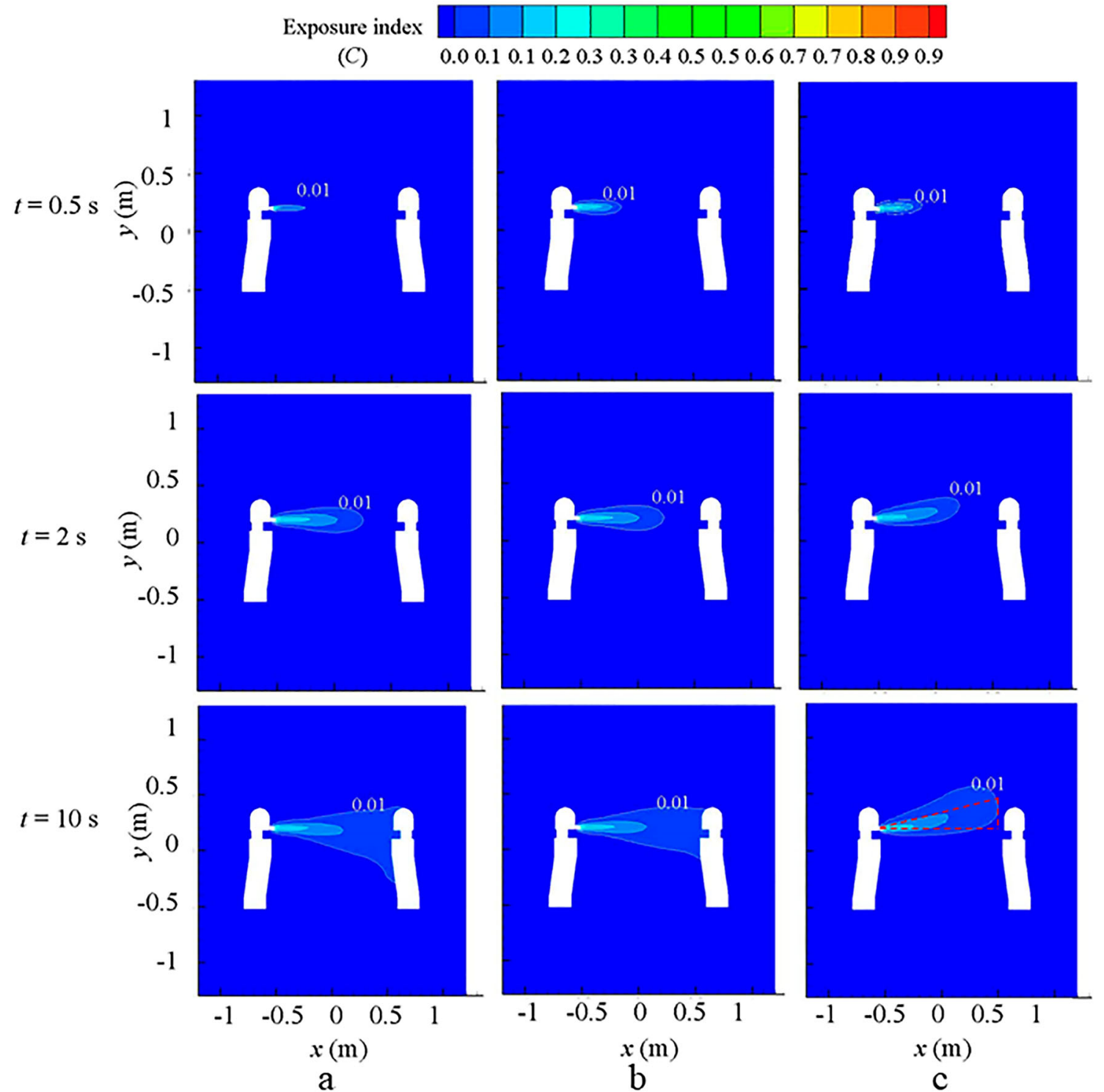

Fig. 5 The distribution of exposure index $C$ when the exposure time is $0.5 \mathrm{~s}, 2 \mathrm{~s}$ and $10 \mathrm{~s}$, respectively. (a) Stable condition, (b) neutral condition and (c) unstable condition [15]

more controlled by the inertia of the mainstream of the contaminant flow instead of the indoor air stability conditions.

When Manikin A has been exposed to the infectious contaminant for $2 \mathrm{~s}$ (Fig. $5 \mathrm{a}, \mathrm{b}$ and $\mathrm{c}, t=2 \mathrm{~s}$ ), the distribution of exposure index has occupied two-thirds of the breathing zone in three conditions. In the stable and neutral conditions (Fig. $5 \mathrm{a}$ and $\mathrm{b}, t=2 \mathrm{~s}$ ), the exposure index distributes horizontally forwards to Manikin A, whereas it shows a clear upward trajectory in the unstable condition (Fig. $5 \mathrm{c}, t=2 \mathrm{~s}$ ). The characteristics of the distribution of the exposure index are in line with the vector distribution in Fig. 4. As there is no temperature difference between the released contaminant and the ambient air at the releasing height, the trajectory of the contaminant is only influenced by the indoor air stability. In the neutral condition, the vertical temperature difference between the room top and the bottom is zero, which indicates that the contaminant is driven by its inertia. The movement of contaminants is along the horizontal direction. In the stable condition, the released contaminant, apart from its inertia, experiences a confinement effect resulted from the positive temperature gradient in the room, which limits the vertical movement of the contaminant. Therefore, the trajectory of the contaminant in the stable condition maintains in the horizontal direction, which is the same as that of the neutral condition, whereas in the unstable condition, warmer air rises from the bottom and pushes the contaminant upwards. The distributions of the exposure index for the stable, neutral and unstable cases properly illustrate the character of the effect of the indoor air stability on the flow dynamics of contaminants.

When the exposure time is $10 \mathrm{~s}$, Manikin A is fully exposed to the contaminant in the breathing zone in the stable and neutral condition (Fig. 5a and b, $t=10 \mathrm{~s}$ ), especially, the 
distribution of exposure index has covered Manikin A from the head to the stomach area in the stable condition, whereas in the unstable condition (Fig. $5 \mathrm{c}, t=10 \mathrm{~s}$ ), the distribution of the exposure index reflects that the released contaminant has significantly deviated from the centreline of the breathing zone and tends to flow above Manikin A's head, with the inclination percentage of $24.76 \%$.

\section{The distribution of exposure index along sampling lines}

From the above analysis, slight differences are observed regarding the distribution of the exposure index between stable and neutral conditions; thereby in this section, only the results for stable and unstable conditions are used for further analysis. As can be seen from Fig. 6a, line $l$ is established along the central line between the contaminant source and Manikin A. Exposure index along line 1 is obtained to represent the contaminant dispersion and personal exposure in the mainstream direction; line $a$ and line $b$ are perpendicular to line $l$ in a range of $-0.6 \mathrm{~m}<y<1.0 \mathrm{~m}$ at $x=0 \mathrm{~m}$ and $x=0.4 \mathrm{~m}$, respectively, to capture the vertical distribution of the exposure index.

Figure $6 \mathrm{~b}$ compares the distribution of the exposure index along line $l$ of stable and unstable conditions at $t=2 \mathrm{~s}$ and $t=$ $10 \mathrm{~s}$. The exposure index near the contaminant source is the highest, approximately equals to 0.225 . Then the exposure index drops to 0.18 at point $m$. As the released contaminant transports to Manikin A, the difference of exposure index between the stable and unstable begins to occur. For $t=2 \mathrm{~s}$ and $t=10 \mathrm{~s}$, the exposure index in the stable condition is always higher than that in the unstable condition. When $t=$ $2 \mathrm{~s}$, the exposure index decreases to zero at point $n(x=0.32$ $\mathrm{m})$, which indicates that the released contaminant has not yet transported to Manikin A. When $t=10 \mathrm{~s}$, the released contaminant has arrived at Manikin $\mathrm{A}(x=0.5 \mathrm{~m})$, and the difference of the exposure index between stable and unstable conditions is obvious, with 0.03 of the stable case, which is four times larger than that of the unstable case.

Figure 7a presents the vertical distribution of the exposure index along the line $a$ of stable and unstable conditions at $t=$ $2 \mathrm{~s}$ and $t=10 \mathrm{~s}$. The exposure index for the unstable condition is nearly the same as that for the stable condition. This indicates that the contaminant level at $0.5 \mathrm{~m}$ in front of the source is mainly dependent on the initial contaminant flow rather than the air distribution pattern in the room. For the stable condition, the largest exposure index along line $a$ is 0.082 at $y=0.2 \mathrm{~m}$ (contaminant releasing height), while it is 0.077 at around $y=0.3 \mathrm{~m}$ for the unstable condition. This reveals that the contaminant disperses to a wider area in the unstable condition than in the stable condition.

Figure $7 \mathrm{~b}$ shows the vertical distribution of the exposure index along line $b$ (in the vicinity of Manikin A) of the stable and unstable conditions when $t=2 \mathrm{~s}$ and $t=10 \mathrm{~s}$. The exposure index for stable and unstable conditions is 0 when the exposure duration is $2 \mathrm{~s}$. This is because the released contaminant has not yet reached the vicinity of Manikin A. When $t=$ $10 \mathrm{~s}$, the distribution of the exposure index in the unstable condition covers a relatively larger area $(-0.4 \mathrm{~m}<y<1.0$ $\mathrm{m})$ when compared with that in the stable condition $(-0.4 \mathrm{~m}$ $<y<0.6 \mathrm{~m}$ ); however, the peak value for the unstable condition is lower than that of the stable condition, which is 0.016 at the height of $0.4 \mathrm{~m}$ for the unstable condition and is 0.04 at $y=$ $0.1 \mathrm{~m}$ for the stable condition. The exposure index of the unstable condition is $40 \%$ of that in the stable condition.

\section{The distribution of exposure intensity of different indoor air stability conditions}

Figure 8a shows the concentration of contaminant near Manikin A's nose at different exposure times. At the first 2
Fig. 6 (a) Configuration of the location of sampling lines $a, b$ and $l$ and (b) comparison of the variation of exposure index $C$ with horizontal distance (along line $l$ ) of stable and unstable conditions at $t=2 \mathrm{~s}$ and $t=10 \mathrm{~s}$ [15] a

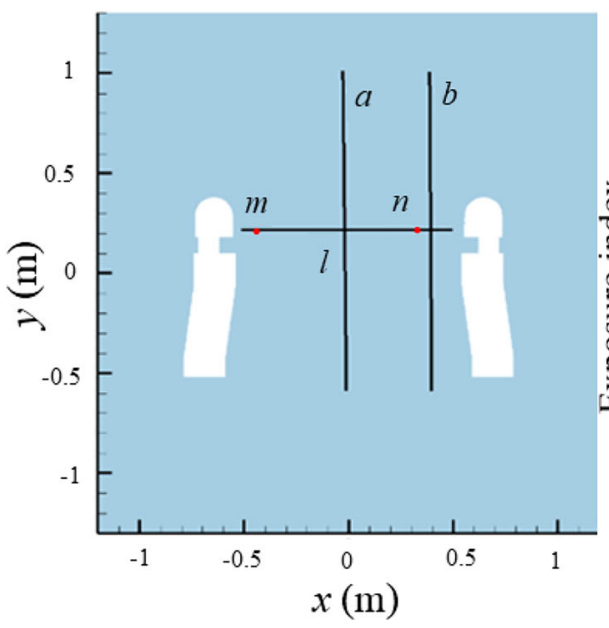

b

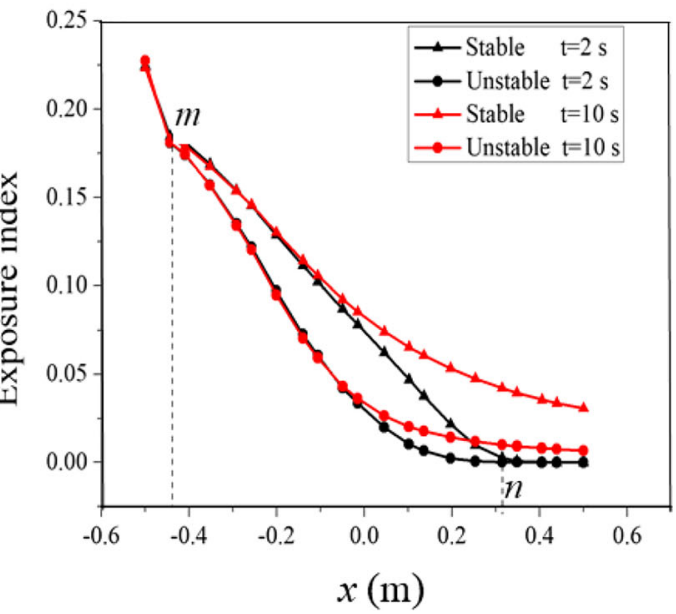


Fig. 7 Comparison of the distribution of exposure index $C$ along sampling lines of stable and unstable conditions at $t=2 \mathrm{~s}$ and $t$ $=10 \mathrm{~s}(\mathbf{a})$ along line $a$ and (b) along line $b$
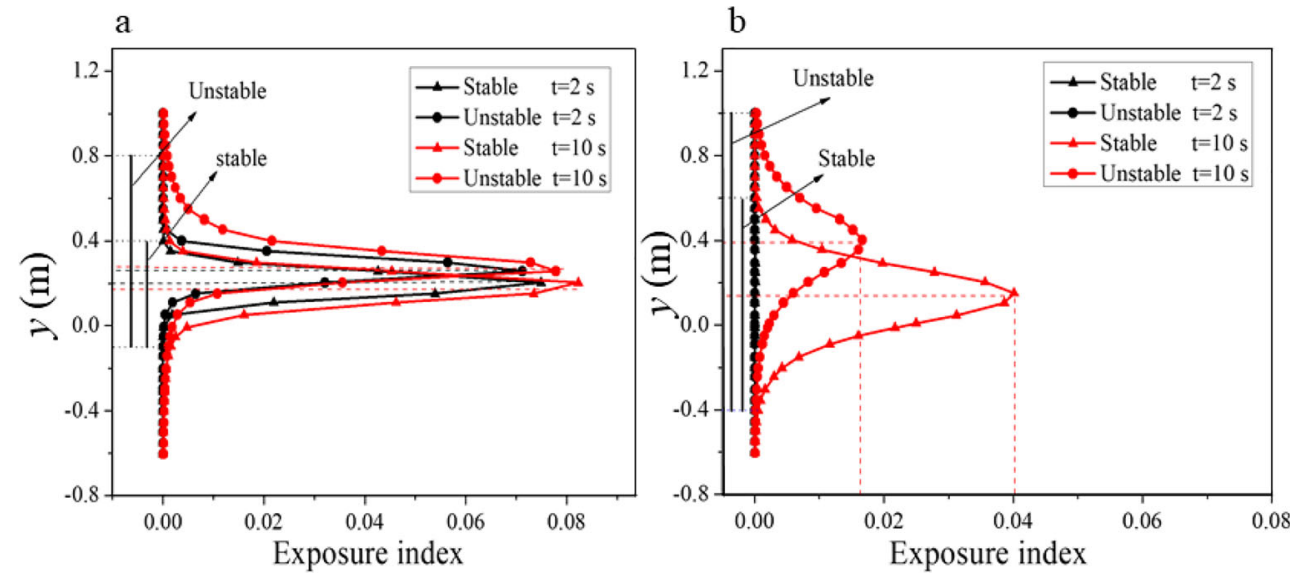

s, nearly no difference in the concentration is observed between stable and unstable conditions. This is because, as mentioned before, the released contaminant has not arrived at the vicinity of Manikin A when the exposure time is $2 \mathrm{~s}$. With the increase of the exposure duration, the difference of concentration begins to show up. The stable condition has a faster increasing rate, reaching $2.39 \times 10^{-2} \%$ when the exposure time is $10 \mathrm{~s}$, while the concentration for the unstable condition experiences a relatively gentle change, increasing to $4.9 \times$ $10^{-3} \%$ at the end of the simulation.

Figure $8 \mathrm{~b}$ presents the exposure intensity of Manikin A in the breathing zone. Obviously, the exposure intensity of the stable condition is always the highest at different exposure times. When $t=4 \mathrm{~s}$, exposure intensities are relatively small for stable and unstable conditions. Especially in the unstable condition, the exposure intensity is nearly zero. The exposure intensity grows with time. When $t=10 \mathrm{~s}$, the exposure intensity of the unstable condition is $0.0165 \%$, whereas it increases to $0.115 \%$ of the stable, which is nearly seven times larger than that of the unstable condition.

\section{Discussion}

When comparing the distribution of velocity vector in stable, neutral and unstable conditions (Fig. 4), it is found that the three conditions share similar vector distributions near the contaminant source where the largest velocity appears. However, in the centreline between the contaminant source and Manikin A, the vector distribution in the stable condition (Fig. 4a) is relatively denser than that in the unstable condition (Fig. 4c). This indicates that the stable condition may trap most of the contaminant in the breathing zone of Manikin A, whereas in the unstable condition, the contaminant is more easily to disperse to a relatively wider area out of the breathing zone.

It is demonstrated in Fig. 5 that the distribution of the exposure index in the stable condition is more likely to concentrate in the mainstream direction with less vertical diffusion when compared with the unstable condition. This is because the stably stratified temperature confines the contaminant mainstream to a limited layer close to the height where it is
Fig. 8 (a) The variation of the contaminant concentration near the Manikin A's nose and (b) exposure intensity $E$ of the inhalation manikin at different exposure times

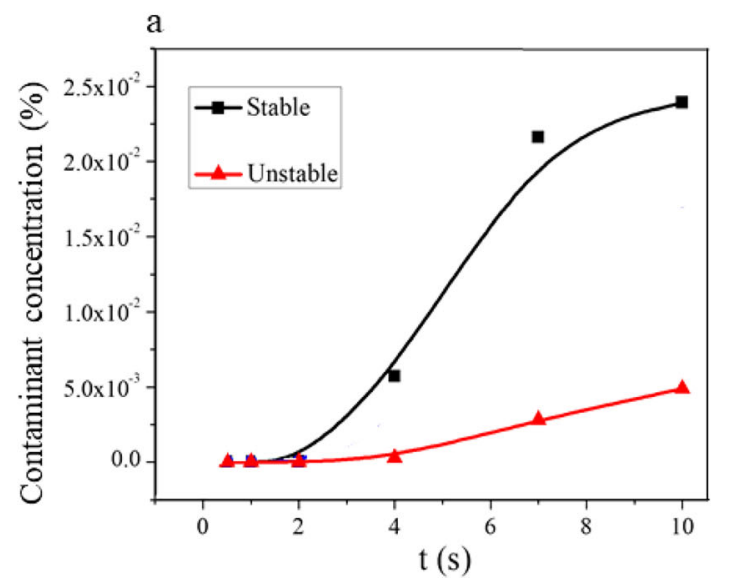

b

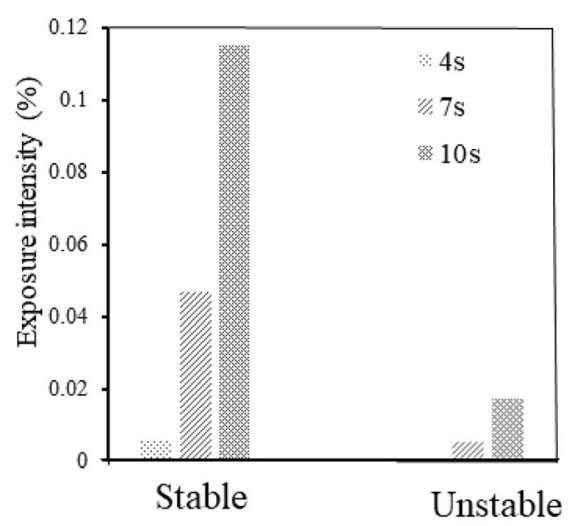


released; thus the majority of the contaminant penetrates straightly towards Manikin A, leading to a highly infectious breathing zone. This result is in agreement with that reported by Gao and Niu (2006). On the contrary, in the unstable condition, the buoyance effect of the hot air from the bottom promotes vertical diffusion of the released contaminant (Fig. $4 \mathrm{c})$; therefore, the released contaminant is more easily to divert from its initial direction and diffuses to a larger area out of the breathing zone, resulting in a less contaminated breathing area, which has also been illustrated in Figs. $6 \mathrm{~b}$ and 7 where fewer contaminant has transported to the vicinity of Manikin A in the unstable condition when compared with the stable condition. As exposure duration increases, the exposure intensities for both the stable condition and the unstable condition increase, with the stable condition increasing far more rapidly than the unstable condition (Fig. 8), which implies that people will be at a higher risk of being exposed to the infectious contaminant in the breathing microenvironment in stable conditions than in unstable conditions.

One of the practices of this study is that it indicates that people will have a greater risk of being infected when they are exposed to the infectious disease carriers, for example, the COVID-19 patients, in a stable environment. Though the temperature of the released contaminant in this study is not the same as the respiratory temperature, the effect of indoor air stability on regulating indoor airflow distribution revealed in this study is universal. As this current study reveals, when the exposure time was $10 \mathrm{~s}$, the exposure index in the unstable condition is $40 \%$ of that in the stable condition (Fig. 7b), and the exposure intensity in the unstable environment is only one-seventh of that in the stable environment (Fig. 8b); thus we can expect that when a healthy body interacts with a sick person who carries infectious pathogens in a stable environment for a considerable amount of time, the healthy body will have much higher exposure intensity than they are in unstable environments. Cases will be worse when children, the elderly and people with different diseases involve in such an environment, who are more vulnerable to harmful substances. Whereas the unstable condition is more efficient in removing the contaminant from the breathing zone, so people in an unstable condition is less likely to be infected. In this regard, the unstable environment is recommendable in reducing infection risks to the contaminant in the breathing zone.

Another practice contribution of this study is guiding for building ventilation design. Take a mixing ventilated room, for example, mixing ventilation provides an intense mixing effect into the indoor air environment to dilute the contaminant in the breathing zone (Cao et al. 2014). The higher the ventilation rate is, the lower the contaminant concentration in the breathing zone will be. The characteristics of mixing ventilation are similar to the mechanism of the unstable condition, where turbulent mixing rises by the warm air near the floor in the indoor environment. Normally, unstable conditions can be developed by an air carrying energy radiant-air-conditioning system, which has been demonstrated to be an energyefficient form of air-conditioning system (Gong et al. 2017). Therefore, it is feasible to apply mixing ventilation and an unstable condition in one room to achieve the equivalent clean breathing zone as a solely mix ventilated room obtains while the former requires a much lower ventilation rate. Additionally, a displacement ventilation system may yield thermal stratification in the indoor environment (Bjørn and Nielsen 2002), which is similar to the temperature distribution in a stable condition. When the displacement ventilation system is combined with stable conditions, an intensified thermal stratification is presumably obtained. This combination is applicable in indoor environments where displacement ventilation shows better efficiency in removing the indoor contaminant. It is inferred that by integrating proper indoor air stability conditions with ventilation systems, the energy consumption of the building ventilation system can be potentially reduced.

\section{Limitations and implications for future research}

The presented work is considered a preliminary assessment of the influence of indoor air stability on the distribution of exhaled pollutants and personal exposure in the human breathing microenvironment. To highlight the objective of this study and to focus on the effect of the background temperature effect, i.e. buoyancy effect driven by indoor air stability, the Archimedes-related buoyancy effect is excluded from the scope of the current work, i.e. the body thermal plume was not considered. Further studies that combine two buoyancy effects, namely, the Archimedes-related buoyancy effect and indoor-air-stability-related buoyancy effect, are necessary. Also, we simplified some of the boundary conditions in the numerical simulation, for example, the inhalation velocity of manikin A was regarded as constant. Follow-up studies will consider more complicated boundary conditions. In addition to body thermal plume and breathing activity, subsequent research will focus on designing full-scale experiments with real human participating in, and various ventilation methods, personnel behaviour, and pollution source locations will be included to comprehensively consider the impact of indoor air stability on contaminant distribution and disease transmission in complex indoor environments. Moreover, the model room in this study is an ideal environment with few disturbances, but in general indoor environments, activities involving multiple persons could exist. Therefore, the influence of activities among multiple persons on the contaminant concentration in breathing microenvironmental is also worthy of further research and discussion. 


\section{Conclusion}

This paper presents a numerical simulation of personal exposure to the airborne infectious contaminant in the breathing zone. Three indoor air stability conditions, namely, stable, neutral and unstable, are considered. In the stable condition, due to the confinement effect of the temperature stratification, the contaminant tends to keep its initial inertia state and transport straightly to Manikin A's breathing zone, resulting in a high level of exposure index, whereas in the unstable condition, due to the rising warm air from the bottom, the contaminant mainstream diverts from its initial direction before reaching Manikin A at an inclination percentage of $24.76 \%$, so the infectious contaminant disperses effectively from Manikin A's breathing zone. In general, the exposure index in the unstable condition is $40 \%$ of that in the stable condition, and the exposure intensity in the unstable environment is only one-seventh of that in a stable environment. From the perspective of protecting people from being infected, the unstable condition is recommended for unventilated indoor environments to effectively reduce the exposure level. This study demonstrates the importance of indoor air stability on personal exposure in the indoor environment and provides a new direction for future study of personal exposure reduction in the indoor environment. The presented work is considered a preliminary assessment of the effect of indoor air stability on the flow characteristics of airborne infectious contaminant. Further detailed research will be carried out concerning the combination of indoor air stability and typical ventilation systems.

Acknowledgements We would like to thank Dr Andrea Coschignano and Mrs Nicola Cavaleri for reviewing the language.

Author contribution Xiaorui Deng: data curation and writing. Guangcai Gong: supervision, project administration and funding acquisition. Shanquan Chen: review and editing. Xizhi He: investigation. Yongshen Ou: visualization. Yadi Wang: software.

Funding This study was funded by the National Natural Science Foundation of China (No.51378186), the National Science \& Technology Supporting Program (No. 2015BAJ03B00) and the China Scholarship Council (No. 201806130150)

Availability of data and material The datasets used or analysed during the current study are available from the corresponding author on reasonable request.

\section{Declarations}

Ethics approval and consent to participate Not applicable

Consent for publication Not applicable

Competing interests The authors declare no competing interests.

\section{References}

Aganovic A, Steffensen M, Cao G (2019) CFD study of the air distribution and occupant draught sensation in a patient ward equipped with protected zone ventilation. Build Environ 162:106279

Ai Z, Mak CM, Gao N, Niu J (2020) Tracer gas is a suitable surrogate of exhaled droplet nuclei for studying airborne transmission in the built environment. Build Simul 13:1-8

Alamdari F, Butler DJG, Grigg PF, Shaw MR (1998) Chilled ceilings and displacement ventilation. Renew Energy 15:300-305

Allen JG, MacNaughton P, Satish U, Santanam S, Vallarino J, Spengler JD (2016) Associations of cognitive function scores with carbon dioxide, ventilation, and volatile organic compound exposures in office workers: a controlled exposure study of green and conventional office. Environ Health Perspect 124:805-812

Bivolarova M, Kierat W, Zavrl E, Popiolek Z, Melikov A (2017) Effect of airflow interaction in the breathing zone on exposure to bioeffluents. Build Environ 125:216-226

Bjørn E, Nielsen PV (2002) Dispersal of exhaled air and personal exposure in displacement ventilated rooms. Indoor Air 12:147-164

Cao G, Awbi H, Yao R, Fan Y, Sirén K, Kosonen R, Zhangn J (2014) A review of the performance of different ventilation and airflow distribution systems in buildings. Build Environ 73:171-186

Chen Q (1995) Comparison of different $\mathrm{k}-\varepsilon$ models for indoor air flow computations. Numer Heat Tr B Fund 28:353-369

Dehghan MH, Abdolzadeh M (2018) Comparison study on air flow and particle dispersion in a typical room with floor, skirt boarding, and radiator heating systems. Build Environ 133:161-177

Deng X, Gong G (2020) Comparison of the performances of mixing ventilation and displacement ventilation under different indoor air stability conditions in a space capsule. Microgravity Sci Tec 32: 749-759

Douwest J, Thorne P, Pearce N, Heederik D (2003) Bioaerosol health effects and exposure assessment: progress and prospects. Ann Occup Hyg 47:187-200

Duguid JP (1946) The size and duration of air-carriage of respiratory droplets and droplet-nuclei. J Hyg 44:471-479

Fisk WJ (2018) How home ventilation rates affect health: a literature review. Indoor Air 28:473-487

Fisk WJ, Mirer AG, Mendell MJ (2009) Quantitative relationship of sick building syndrome symptoms with ventilation rates. Indoor Air 19: $159-165$

Gao N, Niu J (2004) CFD study on micro-environment around human body and personalized ventilation. Build Environ 39:795-805

Gao N, Niu J (2006) Transient CFD simulation of the respiration process and inter-person exposure assessment. Build Environ 41:1214-1222

Gao N, Niu J (2007) Modeling particle dispersion and deposition in indoor environments. Atmos Environ 41:3862-3876

Gao N, He Q, Niu J (2012) Numerical study of the lock-up phenomenon of human exhaled droplets under a displacement ventilated room. Build Simul 5:51-60

Gong G, Deng X (2017) Nature and characteristics of temperature background effect for interactive breathing process. Sci Rep 7:8549

Gong G, Han B, Luo H, Xu C, Li K (2010) Research on the air stability of limited space. Int J Green Energy 7:43-64

Gong G, Liu J, Mei X (2017) Investigation of heat load calculation for air carrying energy radiant air-conditioning system. Energy Build 138: 193-205

Han B, Hu L, Bai Z (2017) Personal exposure assessment for air pollution. In: Dong GH (ed) Ambient air pollution and health impact in china, advances in experimental medicine and biology. Springer, Singapore, pp 27-57

He Q, Niu J, Gao N, Zhu T, Wu J (2011) CFD study of exhaled droplet transmission between occupants under different ventilation strategies in a typical office room. Build Environ 46:397-408 
Holmberg S, Li Y (1998) Modelling of the indoor environment-particle dispersion and deposition. Indoor Air 8:113-122

Kierat W, Bivolarova M, Zavrl E, Popiolek Z, Melikov A (2018) Accurate assessment of exposure using tracer gas measurements. Build Environ 131:163-173

Licina D, Melikov A, Sekhar C, Tham KW (2015) Air temperature investigation in microenvironment around a human body. Build Environ 92:39-47

Melikov A (2015) Human body micro-environment: the benefits of controlling airflow interaction. Build Environ 91:70-77

Mendez C, San Jose JF, Villafruela JM, Castro F (2008) Optimization of a hospital room by means of CFD for more efficient ventilation. Energy Build 40:849-854

National Research Council (1991) Personal exposure assessment for airborne pollutants: advances and opportunities. National Academy Press, Washington, DC

Nielsen PV (1975) Prediction of air flow and comfort in air conditioned spaces. ASHRAE Trans 81:247-259

Nielsen PV, Jensen RL, Litewnicki M, Zajas JJ (2009) Experiments on the microenvironment and breathing of a person in isothermal and stratified surroundings. In Healthy Buildings 2009: 9th International Conference \& Exhibition, Syracuse, New York

Olesen BW (1997) Possibilities and limitations of radiant floor cooling. ASHRAE Trans 103:42-48

Olmedo I, Nielsen PV, Ruiz de Adana M, Jensen RL, Grzelecki P (2012) Distribution of exhaled pollutants and personal exposure in a room using three different air distribution strategies. Indoor Air 22:64-76

Pantelic J, Sze-To GN, Tham KW, Chao CYH, Khoo YCM (2009) Personalized ventilation as a control measure for airborne transmissible disease spread. J R Soc Interface 6:S715-S726

Peng P, Gong G, Mei X, Liu J, Wu F (2019) Investigation on thermal comfort of air carrying energy radiant air-conditioning system in south-central China. Energ Buildings 182:51-60

Peng P, Gong G, Deng X, Chun L, Li W (2020) Field study and numerical investigation on heating performance of air carrying energy radiant air-conditioning system in an office. Energ Buildings 209: 109712

Rim D, Novoselac A (2009) Transport of particulate and gaseous pollutants in the vicinity of a human body. Build Environ 44:1840-1849
Safizadeh MR, Watly L, Wagner A (2019) Evaluation of radiant heating ceiling based on energy and thermal comfort criteria, part ii: a numerical study. Energies 12:3437

Spengler JD, Sexton K (1983) Indoor air pollution: a public health perspective. Science 221:9-17

Sundell J, Levin H, Nazaroff WW, Cain WS, Fisk WJ, Grimsrud DT, Gyntelberg F, Li Y, Persily AK, Pickering AC, Samet JM, Spengler JD, Taylor ST, Weschler CJ (2011) Ventilation rates and health: multidisciplinary review of the scientific literature. Indoor Air 21: 191-204

Taghinia J, Rahman MM, Siikonen T (2015) Numerical simulation of airflow and temperature fields around an occupant in indoor environment. Energy Build 104:199-207

Villafruela JM, Olmedo I, Adana MR et al (2013) CFD Analysis of the human exhalation flow using different boundary conditions and ventilation strategies. Build Environ 62:191-200

Wang Y, Gong G, Xu C, Yang Z (2014) Numerical investigation of air stability in space capsule under low gravity conditions. Acta Astronaut 103:81-91

Watson AY, Bates RR, Kennedy D (1988) Air pollution, the automobile, and public health. National Academy Press, Washington, DC, p 212

Xu C, Nielsen PV, Gong G, Jensen RL, Liu L (2015) Influence of air stability and metabolic rate on exhaled flow. Indoor Air 25:198-209

Zhang X, Wargocki P, Lian Z, Thyregod C (2017) Effects of exposure to carbon dioxide and bioeffluents on perceived air quality, selfassessed acute health symptoms, and cognitive performance. Indoor Air 27:47-64

Zhou Y, Deng Y, Wu P, Cao S (2017) The effects of ventilation and floor heating systems on the dispersion and deposition of fine particles in an enclosed environment. Build Environ 125:192-205

Zhou X, Liu Y, Luo M, Zhang L, Zhang Q, Zhang X (2019) Thermal comfort under radiant asymmetries of floor cooling system in $2 \mathrm{~h}$ and $8 \mathrm{~h}$ exposure durations. Energy Build 188-189:98-110

Publisher's note Springer Nature remains neutral with regard to jurisdictional claims in published maps and institutional affiliations. 